Jason Martin

\title{
Daring librarianship What library leaders can learn from Brene Brown
}

B

rene Brown is a research professor at the University of Houston who studies courage, vulnerability, shame, and empathy. Her books Daring Greatly and Dare to Lead explore how vulnerability can help us lead fulfilled lives and become courageous leaders. Brown's writing has something for everyone, including library leaders. This article addresses Brown's definitions of vulnerability and leadership and then briefly explores the three key benefits of vulnerability for library leaders: courage, clarity, and connection.

\section{Vulnerability}

Brown defines vulnerability "as the emotion that we experience during times of uncertainty, risk, and emotional exposure." ${ }^{1}$ Being vulnerable does not make us weak. In fact, vulnerability helps us build courage and face the unknown change that trying something new brings. Vulnerability is part of each and every moment of living a full life. We can try to protect ourselves against the negative aspects of being vulnerable, but when we do so we shut out everything positive that comes from being vulnerable, including love, trust, and courage. Vulnerability helps us build trust-crucial for library leaders-but we also need trust in order to be vulnerable. Vulnerability is not indiscriminate disclosure of the details of our lives. Rather, true vulnerability requires connection, trust, and a reciprocity of vulnerability.

Practicing vulnerability-being vulnerable-is difficult for me, as it as for almost everyone. But vulnerability is important for me as a library leader because it helps me build trust, create connection with others, and grow courage. Vulnerability also allows me to have difficult conversations, whether one-on-one or in a group setting, that my library and all kinds of other libraries need to have, from giving constructive feedback to managing disruptive behaviors to holding frank conversations about fear, shame, and inclusion. This often means saying, "I do not have an answer, but this is important and we need to do something about it." As library leaders, we are often expected to have all the answers. Admitting that I do not is being vulnerable in a very big way.

\section{Leadership}

Brown defines a leader "as anyone who takes responsibility for finding the potential in people and processes, and who has

Jason Martin is interim dean at Middle Tennessee State University's James E. Walker Library, email: jason. martin@mtsu.edu

๑) 2020 Jason Martin 
the courage to develop that potential." In practice this requires library leaders to recognize and understand the strengths, weaknesses, and aspirations of those who they supervise, coach, and mentor in the library. Not everyone in my library wants to be a library dean or department head, but that does not mean I do not coach them in their careers.

In order to effectively develop a librarian or staff member, I need to know where that person wants to go, how fast they want to get there, and where they are now, and then I must serve and help them to get from where they are to where they want to be.

Another aspect of effective library leadership is honest self-awareness. Without introspection we cannot grow. I build in time to reflect on the kinds of questions vulnerability requires us to ask ourselves. I work to honestly answer the questions, "Am I the leader I want others in this library to be? Am I practicing the kinds of behaviors, attitudes, values, and norms I want others in this library to practice?"

\section{Courage}

"Vulnerability is not winning or losing. It's having the courage to show up when you can't control the outcome."

Courage is essential for good leadership. Leaders need to have the courage to do the things that need to be done, say the things that need to be said, even when (maybe especially when) it is uncomfortable and inconvenient. Vulnerability is the path to courage. Without taking risks, braving uncertainty, and exposing ourselves emotionally, we cannot be courageous. In fact, "rumbling with vulnerability" is one of the four skills Brown defines for courage. The other three are adhering to our values, trust, and how to accept and deal with failure. ${ }^{4}$

The great thing about courage is it is infectious. A courageous library leader inspires courage throughout the library. Sometimes we will ask others or ourselves what we would do if we knew we could not fail. This question is designed to inspire, but a far better question is the one Brown asks of leaders, "What's worth doing even if I fail?" I know that my answer to that question is what will make me truly courageous as a library leader-and in life. This is not a question I answer once, but on a continuous basis. Honestly, I do not always have answers, but I aspire to and work towards being a leader who does have answers and the courage to follow through on them.

\section{Clarity}

"Clear is kind. Unclear is unkind."

In order for vulnerability to truly work, we must establish firm boundaries around what is and what is not allowed, both by us and by others. These boundaries help contain courageous conversations and acts on their true path and not have them veer off into areas of "confession, manipulation, desperation, or shock and awe."

Clarity is also essential to library leaders when it comes to defining expectations and giving feedback. By being clear in expectations and explanations of how someone can improve, I know that I am helping them far more than by beating around the bush and hedging my bets. Leaders must also be clear about their values, and whether they represent and live those values each day. My values are my fuel for practicing vulnerability, being courageous, and doing the right things instead of the easy things. I use my values to help carry me through difficult times.

\section{Connection}

"Daring leaders must care for and be connected to the people they lead."

In order to make these important connections, to build the relationships needed to be a successful leader and have a well-functioning organization, library leaders need to use empathy. Brown lists five important parts of being empathetic: understand the perspective of the other person, do not judge, understand their 
feelings, let them know you understand their feelings, and be present with that person.? Empathy is also important in battling shame. Too often our library cultures are ones of scarcity. We are told there is not enough money, time, or people, so we need to do more with less. This mindset produces shame in individuals who never think they are doing enough or doing as well as everyone else. An organization of shame is one filled with bullying, backstabbing, gossiping, and disengagement. Empathy is the key to combating shame and creating a healthy library workplace and culture. In order to create an empathetic library-where everyone is free to be themselves-I must let individuals know they are valued and create a sense of belonging.

\section{Conclusion}

By practicing vulnerability, library leaders can become more courageous, gain clarity around their values and boundaries, and make connections with the people they work with. Many people see being vulnerable as a weakness, but vulnerability builds strength, and it takes strength to be vulnerable.

Nothing truly significant in our lives is accomplished without facing uncertainty, risk, and emotional exposure that being vulnerable brings.

\section{Further resources}

Brene Brown, "Dare to Lead Hub." https://daretolead.brenebrown.com/ (accessed October 1, 2019).

\section{Notes}

1. Brene Brown, Dare to lead (New York: Random House, 2018), 19.

2. Brown, Dare to lead, 4.

3. Brown, Dare to lead, 19.

4. Brown, Dare to lead, 10.

5. Brene Brown, Daring greatly (New York: Avery, 2012), 42.

6. Brown, Dare to lead, 47.

7. Brown, Dare to lead, 39.

8. Brown, Dare to lead, 12.

9. Brown, Dare to lead, 143-48. n

\section{NEW FROM ACRL PRESS}

International, Transfer, First-Generation, and Re-Entry Students

edited by Ngoc-Yen Tran and Silke Higgins

All titles are available in the ALA Store at

http://www.alastore.ala.org

The 360 Librarian: in the Workplace

Supporting Today's Students in the Library:

Strategies for Retaining and Graduating

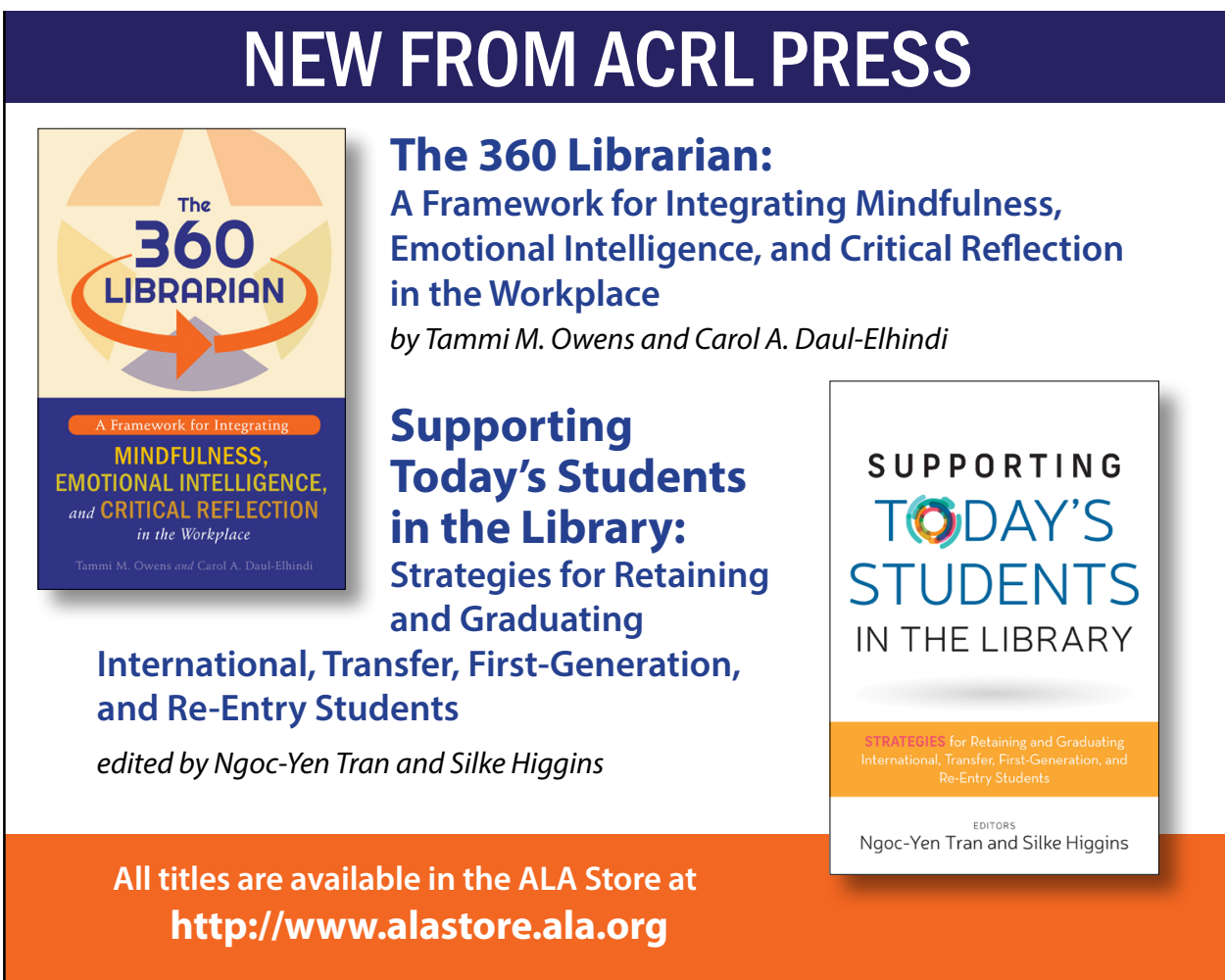

A Framework for Integrating Mindfulness, Emotional Intelligence, and Critical Reflection

by Tammi M. Owens and Carol A. Daul-Elhindi 